\title{
Identidad social y prácticas discursivas en línea de estudiantes de español como lengua extranjera
}

\section{Social Identity and Discursive Practices Online for Students of Spanish as a Foreign Language}

\author{
AliCIA HERNANDO \\ Facultad de Educación, Centro de Formación del Profesorado, UCM \\ aliher05@ucm.es \\ https://orcid.org/0000-0003-2824-5897
}

Recibido: 20/11/2019 Aceptado: 02/12/2019

Cómo citar: Hernando, Alicia (2019). "Identidad social y prácticas discursivas en línea de estudiantes de español como lengua extranjera”, Revista Estudios del Discurso Digital (REDD), 2: 60-100

DOI: https://doi.org/10.24197/redd.2.2019.60-100

Resumen: El artículo presenta un estudio de carácter exploratorio y descriptivo, que forma parte de una investigación más amplia, en la que se analizan las relaciones entre las prácticas y actividades letradas en dos espacios digitales, Facebook e Instagram, y la forma en la que los usuarios deciden poner de manifiesto sus valores, creencias e identidad(es) de manera pública ante los demás. El objetivo de este estudio en concreto es 1. comprobar cuáles son las prácticas vernáculas a partir de las cuales construyen los discursos que formulan en Facebook e Instagram; y 2. establecer la relación entre el diseño y configuración de una y otra red en relación a la manera en la que escriben y el tipo de textos y contenido multimodal que comparten en una y otra red social. En el estudio se analizaron los mensajes y actualizaciones de estado en Facebook e Instagram de 11 estudiantes universitarios de origen extranjero. El corpus se analizó por una parte, categorizando el tipo de textos o contenido multimodal (tanto propio como ajeno) que compartían en Facebook e Instagram; y por otra, procediendo a un análisis discursivo de sus textos, tomando en consideración algunos de los elementos propuestos por Hymes (1972). Se tomó como unidad de análisis el texto entendido como un evento comunicativo multimodal (Krees y Leeuwen, 2001), integrado por elementos léxicos y audiovisuales: imágenes, emojis y emoticonos, hashtags, enlaces, etc. Los resultados se triangularon con una entrevista semiestructurada en línea, con el objetivo de que los estudiantes pudieran validar o rechazar las interpretaciones y significados surgidos a partir del análisis discursivo.

Palabras claves: identidad; prácticas letradas; multiliteracidad; multimodalidad; enseñanza de lenguas 


\begin{abstract}
The article presents a descriptive study, part of a broader research, that explores the relationship between literacy practices and activities in two digital spaces, Facebook and Instagram, and the way in which users decide to reveal their values, beliefs and identities in public online spaces to a global audience. The analysis of their texts were used with the purpose of 1 . Demonstrating which are the literacy practices that help them to build their discourse in Facebook and Instagram; 2. Stablishing the relationship between the design and configuration of both networks and the way participants write and share multimodal contents. A total of 11 participants took part in the research, all of whom were foreign students in different Spanish universities or educational institutions. The discourse analysis was carried out categorizing the texts and multimodal content shared; and taking into consideration some of the elements proposed by Hymes (1972). The text is considered as a multimodal communicative event (Krees and Leeuwen, 2001) integrated by lexical and multimodal elements (images, emojis and emoticons, hashtags, links, etc.). The results were triangulated with a semi-structure online interview, with the aim students could validate or reject the interpretations and meanings derived from the discourse analysis.
\end{abstract}

Keywords: identity; literacy practices: multiliteracy; multimodality; language teaching

Sumario: Introducción. 1. Metodología. 2. Necesidades expresivas de los usuarios y las restricciones impuestas por el diseño de las redes sociales en las que participan. 3. El origen intertextual de las voces en el discurso digital. 3.1. Citas directas. 3.2. Citas que no parecen citas. 4. Comunidades de práctica y comunidades imaginadas. 5. Visión social de la escritura en línea. 6. Conclusiones.

Summary: Introduction. 2. Expressive needs and restrictions imposed by the social network design. 3. Intertextual origin of digital discourse voices. 3.1. Direct quotes. 3.2. Hidden quotes. 4. Practice communities and imaginary communities. 5 . Social vision of online writing. 6 . Conclusions.

\title{
INTRODUCCIÓN
}

Las líneas de investigación más importantes seguidas en las dos últimas décadas en relación a la comunicación en línea han seguido fundamentalmente tres caminos de investigación. Nos encontramos, por una parte, la investigación más centrada en los rasgos estructurales que definen y diferencian la comunicación a través de dispositivos, cuyo objetivo principal ha sido la caracterización de los nuevos usos lingüísticos, como las abreviaturas, el uso de emoticonos, el uso de puntuación de manera poco convencional, etc. (Herring, 1996; Baron, 2003; Crystal, 2006). Una de las preocupaciones más importantes para estos autores ha sido determinar si se trata de lengua escrita o lengua hablada, o por el contrario, si al encontrarnos con características de ambos lenguajes, es posible hablar de una auténtica lengua híbrida que tiene sus propias características. Así, de estas reflexiones surgieron en determinados momentos nuevos términos como emailism, Netspeak (Crystal, 2006), y otros que se fueron difundiendo a lo largo de los años, como e-language, chatspeak, cyberlanguage, etc. 
Barton y Lee (2013) señalan cómo al principio se recopilaban una ingente cantidad de datos de los usuarios, que eran analizados sin tener en cuenta las condiciones discursivas o el contexto social de los participantes. A pesar de las importantes aportaciones teóricas, se tendía en ese momento a hacer generalizaciones sobre cuáles eran las convenciones en el uso del lenguaje en línea, fundamentalmente porque no se tomaba en consideración la diversidad. Por ejemplo, hay usos específicos que solo pueden ser explicados a partir de las diferencias individuales, de la personalidad de los usuarios; o de las características específicas, así como sus restricciones o limitaciones, de distintas plataformas, redes sociales, etc.

Otra línea de investigación muy fecunda está formada por los estudios que entienden que los géneros escritos dependen tanto de sus usuarios como de los contextos sociales en los que están insertos (Herring, 2002; Giltrow y Stein, 2009). Abordan el análisis de la lengua en línea desde una perspectiva que tiene en cuenta que, por una parte, es posible encontrar similitudes o diferencias que se van a repetir de manera constante, con cierta regularidad; y por otra, sin embargo, se encuentran cómo son los propios usuarios quienes cambian con frecuencia su manera de escribir en función del propósito comunicativo, reapropiándose de sus palabras, tomando decisiones sobre el uso que hacen de la lengua. Surgen en esta corriente estudios más concretos sobre el uso de la lengua en línea: en blogs (Myers, 2010); o el uso de los mensajes de texto (Tagg, 2012). También es notable el incremento que se observa en los estudios relacionados con la identidad y cómo se representan las identidades sociales en estos nuevos medios. De ahí las investigaciones relacionadas con las diferencias de género (Herring, 1996; Danet, 1998), la representación de la identidad en contextos digitales (Page, 2012), o sobre la perspectiva del usuario en línea (Cherny, 1999).

Por último, una corriente investigadora más reciente, que enmarca una serie de estudios centrados en cómo las formas de comunicación están conformadas de acuerdo a determinadas ideologías, construidas discursivamente en estos nuevos medios. Barton y Lee (2013) señalan de nuevo cómo muchos de estos trabajos toman gran parte de sus ideas e inspiración de disciplinas como la Sociología o los estudios relacionados con la ideología del lenguaje (Blommaert, 1999). Hay varias líneas dentro de esta corriente. Por una parte, lingüistas que estudian cómo se habla en línea, el metalenguaje; por otra, investigadores centrados en todo tipo de contenido multimodal creado por los mismos usuarios, en redes como Flickr (Thurlow y Jaworski, 2011), o Youtube (Chun y Walters, 2011). Lo que más llama la atención es la inclusión en algunos de estos estudios de una mirada crítica y 
eminentemente personal, mediante la que ellos mismos se posicionan y expresan a partir de los datos recabados. La lengua deja de ser vista solo como vehículo de expresión; lo que empieza a ser importante es cómo se representa o malinterpreta la lengua en línea, o por qué se perciben de manera tan negativa públicamente determinados usos, especialmente los relacionados con los jóvenes.

En el artículo, fruto de una investigación más amplia, el foco está puesto en el despliegue de los usos y recursos lingüísticos y multimediales en la medida en la que estos elementos han servido para poder determinar quién es o cómo quiere mostrarse la persona que escribe, cuelga o comparte determinado contenido, propio o ajeno, en línea; qué tipo de contenido escribe y comparte; qué uso hace del medio que utiliza para conseguir su propósito comunicativo; y a quiénes se dirige. El constructo teórico sobre el que está basado el presente trabajo está conformado no solo por el análisis de los recursos y usos lingüísticos y sus prácticas situadas en línea, sino que los sentimientos, valores y percepciones sobre lo que los sujetos participantes de la investigación escriben y comparten son elementos claves para poder desvelar el mensaje que quieren hacer llegar de sí mismos. En definitiva, una perspectiva similar a la que siguen Barton y Lee en su investigación sobre el lenguaje digital (2013). De esta manera, el lenguaje está en el centro del análisis, es el elemento empleado para intentar discernir la relación entre lengua e identidad; el posicionamiento de los sujetos participantes frente a la comunidad de habla de la lengua que están aprendiendo; la relación entre imagen, vídeo, o cualquier otro tipo de contenido multimodal y lengua; las personas del discurso y los papeles que se establecen en las interacciones comunicativas en línea.

El objetivo que guía este trabajo se rige por las siguientes preguntas: i. ¿Qué imagen e identidad quieren proyectar de sí mismos los estudiantes de español como lengua extranjera cuando escriben en esta lengua en línea? ii. ¿Cómo se muestra en los textos y el contenido propio o ajeno que comparten el grado de cercanía o proximidad que existe con los receptores de sus textos (audiencia global, contactos en Facebook e Instagram y amigos)?

\section{Metodología de LA INVESTIGACión}

Se ha abordado el discurso en línea desde dos planos complementarios: en primer lugar, la descripción de los textos, para en un segundo momento pasar a hacer un estudio etnográfico de casos como prácticas situadas. Metodológicamente, la mayor parte de las investigaciones llevadas a cabo 
en el campo de las prácticas letradas adoptan un enfoque etnográfico, con el objetivo de proporcionar respuestas desde la perspectiva de un miembro de la comunidad objeto de estudio. El estudio se encuadra dentro de lo que se denomina enfoque etnográfico virtual (Hine, 2015; Lee, 2011, 2017), en relación con la recogida y análisis de los datos. La observación de las cuentas y perfiles de los sujetos participantes ha sido, de hecho, fundamental. Ha permitido tener acceso a una parte de su mundo, el que dejan ver a sus amigos y conocidos; y entender también qué dinámicas (lingüísticas, de interacción con los demás) operan en sus perfiles y cuentas de Facebook e Instagram. Se incluyen los mensajes y actualizaciones de estado en Facebook e Instagram de 11 estudiantes universitarios de origen extranjero en diferentes momentos de su vida, en periodos que oscilan entre 2013 y 2017. Los sujetos participantes eran en el momento de iniciar la investigación estudiantes extranjeros en universidades o instituciones españolas. Los datos fueron recogidos entre 2014 y enero de 2017, pero el análisis incluye también textos escritos en español anteriores a 2014, generalmente relacionados con el comienzo de su experiencia como estudiantes de español o de su venida a España.

Hay diferencias sustanciales en la frecuencia con la que participaban en sus cuentas y perfiles en línea en español: algunos participantes eran usuarios muy prolíficos, mientras que otros podían dejar pasar incluso semanas sin escribir o compartir algún tipo de contenido. No todos son usuarios de las mismas redes sociales. La mayoría utilizan con más o menos frecuencia Facebook e Instagram, mientras algunos se decantan de manera definitiva por Instagram para comunicarse con sus amigos y contactos. En definitiva, son perfiles muy diversos aunque todos tienen en común el hecho de ser jóvenes de hasta 25 años, estudiantes de español como lengua extranjera en universidades o instituciones españolas en el momento de la investigación y, de manera fundamental, usuarios de Facebook e Instagram en español y otras lenguas. Los datos recogidos de los participantes incluyen los mensajes que han escrito en español en su perfil de Facebook o cuenta de Instagram entre 2013 y enero de 2017 (las fechas varían entre cada participante).

En el análisis discursivo de los textos de los participantes se tomó como unidad de análisis el texto, entendido este como un evento comunicativo multimodal, integrado no solo por elementos léxicos y lingüísticos. En esta conceptualización del texto, lo visual y lo verbal forman una verdadera unidad sintagmática, tal y como proponen Krees y Leewen (2001), de forma que determinados elementos no verbales como las imágenes, los 
emoticonos, las etiquetas (hashtags) e incluso los enlaces, son capaces de explicitar significados y articular determinados aspectos del discurso: las personas que forman parte de la conversación, qué sucede, dónde y cuándo tiene lugar; pero también el propósito y la interpretación que el autor ofrece de su propio texto. En muchas ocasiones, de hecho, es imposible llegar a una interpretación certera de lo quieren expresar los sujetos participantes si dejamos de lado todos estos elementos, porque escriben en medios que facilitan, incentivan e incluso privilegian su uso.

Se ha tenido, asimismo, en cuenta varios modelos. Por una parte, algunos de los elementos del modelo de interacción lingüística de Hymes (1972): quiénes son los que participan en la conversación, en qué situación lo hacen, los instrumentos que emplean para comunicarse y, además, los fines que persiguen, en este caso, motivados por su relación con el resto de co-enunciadores y la comunidad de habla de la lengua que están aprendiendo. Por otra parte, se parte de las aportaciones de la lingüística enunciativa respecto a la enunciación y la deixis (inscripción del "yo", del "tú" y de la $3^{\text {a }}$ persona "él/ella" o el "otro") y, sobre todo, la descripción que establece Goffman desde la sociolingüística interaccional $(1971,1981)$ sobre los papeles y actuaciones presentes en las interacciones comunicativas y los rituales sociales asociados a las mismas, al señalar la distinción entre animador/a, autor/a y portavoz. Se analizan los perfiles de los sujetos participantes en Facebook e Instagram como el lugar en el que se pronuncian y posicionan: 1) expresando sus propios sentimientos e ideas, responsabilizándose no solo de lo que dicen, sino de la forma en que los elementos del texto se organizan para llevar a cabo su propósito comunicativo (autor/a); 2) representando las palabras, ideas y sentimientos de otros (animador/a); y por último 3) dando voz a pensamientos, creencias, ideologías ajenas que pueden llegar a asumirse como propias (portavoz). Facebook e Instagram son, por tanto, el escenario en el que despliegan su representación, mediante la puesta en escena de los papeles ya mencionados, en función no solo de sus necesidades comunicativas y expresivas, sino de la imagen que quieren proyectar, el impacto que quieren causar y cómo desean ser percibidos por los demás.

Esta imagen no es en ningún caso permanente. Por el contrario, cambia, se transforma y es modificada conscientemente. La contabilización del número de veces que aparecen en sus entradas será, por tanto, un indicador de la gestión que hacen en sus cuentas de Facebook e Instagram de sus identidades: cuál es el papel o papeles que predominan, y qué voces son las que se manifiestan en la elaboración de su discurso en línea en español. 
Los participantes ${ }^{1}$ tuvieron conocimiento en todo momento tanto de los objetivos de la investigación, como de los pasos requeridos a medida que se desarrollaba: primera entrevista; análisis de sus textos; segunda entrevista a partir de sus textos. Asimismo, dieron su consentimiento para que sus textos y el contenido relacionado con ellos (el perfil de Facebook y cuenta de Instagram en su conjunto) fueran no solo analizados, sino que formaran parte del contenido de este trabajo. De esta manera, confirmaron estar de acuerdo con que se hiciera uso de su nombre de pila y en algunos casos el apellido (y así se nombran en los ejemplos que se muestran en los siguientes apartados), no quisieron que se empleara un pseudónimo. Sin embargo, se ha optado por eliminar el apellido en el perfil de Facebook, o el nombre de la cuenta en Instagram para evitar cualquier posible invasión de su privacidad cuando empleo los textos a modo de fotografía en el caso de los estudiantes que han manifestado que no quieren que aparezca. En los casos en los que se comenta o analiza las interacciones que mantienen con amigos o contactos concretos, se ha eliminado el apellido de la persona que interacciona con el/la participante, o parte del nombre de la cuenta en Instagram, para evitar que puedan ser identificados.

Además de los textos, se ha tenido en cuenta las imágenes con las que los acompañaban en el caso de que las hubiera; así como las posibles conversaciones (comentarios) que se han iniciado a partir de estos mensajes entre los participantes y otros interlocutores. Por otra parte, también se han recogido resúmenes de entrevistas orales, y las transcripciones de las conversaciones que mantuvimos tras finalizar la lectura y análisis de sus textos a través del chat de Facebook.

Las entrevistas reproducen las palabras originales de los participantes y solo han sido modificadas en aquellos casos en los que había algún tipo de error relacionado con la puntuación, ortografía, etc., que pudiera entorpecer o dificultar la lectura.

\footnotetext{
${ }^{1}$ Los ejemplos que aparecen en los siguientes apartados se corresponden con los de las siguientes estudiantes: Amalie, Corina, Elena, Giusy, Fabiola, Melania, Sam y Somin.
} 


\section{NECESIDADES EXPRESIVAS DE LOS USUARIOS Y LAS RESTRICCIONES IMPUESTAS POR EL DISEÑO DE LAS REDES SOCIALES EN LAS QUE PARTICIPAN}

El análisis discursivo de los textos compartidos en ambas redes por los sujetos participantes hizo necesario que se prestara más atención a las diferencias que Facebook e Instagram presentan en cuanto a su diseño y configuración. Son características que no dependen de los usuarios, pero que sí determinan el tipo de mensajes que escriben, el contenido que comparten, a quiénes se dirigen, etc. En el caso de los perfiles de Facebook, la plataforma es tajante respecto a la presentación de los usuarios. Se prohíben los pseudónimos y los nombres falsos, y se persiguen y eliminan cuentas y perfiles que no siguen esta premisa. Se trata, por otra parte, de una red semipública: los usuarios deben aceptar la solicitud de amistad que alguien les envía antes de que se pueda acceder al contenido de su perfil. Las amistades están ancladas de alguna manera en las relaciones que los usuarios mantienen en la vida real, generando no solo un nuevo tipo de entorno en línea, sino un nuevo modo de producción de la(s) identidad(es) de los usuarios (Zhao et al, 2008). No hay anonimato, sino amigos, conocidos y personas a las que puede interesar conocer. Es frecuente leer actualizaciones de los usuarios de Facebook en las que hacen referencia a la necesidad de reformar su perfil, eliminando de sus conexiones a personas a las que probablemente no conocen más que en Facebook u otras redes sociales, o con las que apenas interaccionan. Los usuarios están conectados persona a persona, y estas conexiones prevalecen sobre el contenido que se publica.

No es así en Instagram. Muchos de sus usuarios no emplean su nombre real y las conexiones que mantienen son diferentes a las que tienen en Facebook. El contenido que crean, producen, distribuyen, es esencial para mantenerles conectados con otros usuarios, en muchas ocasiones desconocidos fuera del mundo de Instagram, pero con intereses y gustos similares. Por supuesto, no hay ningún veto respecto a la manera en que se presentan sus usuarios. Por último, Instagram prioriza el contenido audiovisual sobre los elementos lingüísticos, por lo que es bastante más frecuente encontrarnos en esta red textos breves, conformados por palabras entre etiquetas (hashtags), emojis y emoticonos, y acompañados por una imagen, que funciona como elemento de interacción entre el autor/a y sus receptores.

Estas restricciones de acceso de alguna forma se corresponden con la manera en la que cada una de estas redes conceptualiza y categoriza la 
"amistad": por ejemplo, en Facebook las conexiones de los usuarios se denominan "amigos", mientras que en el caso de Instagram son "seguidores". De manera inevitable, se motiva la producción y distribución de textos con propósitos e intenciones comunicativas diversas. El discurso, diseño y producción de las cuentas de Facebook e Instagram de los estudiantes que han participado en la investigación sirve como ejemplo de un discurso construido a partir de sus prácticas letradas vernáculas, que tienen ancladas sus raíces en su vida diaria. Estos discursos forman parte del conocimiento que se difunde en la actualidad sobre los jóvenes: qué hacen en su día a día (estudios y trabajo; actividades de tiempo libre), con quién se relacionan, quiénes forman parte de su círculo más íntimo y qué tipo de relación o interacciones mantienen con quienes no forman parte del mismo.

Esta diferencia tiene una relevancia especial si pensamos en el uso que hacen de otras lenguas. A menudo tienen en la cabeza dirigirse a personas concretas, pero mientras que en Facebook les leen amigos y conocidos en un sentido amplio, en Instagram pueden llegar a una audiencia desconocida con la que es más fácil conectar si su texto, parte del texto o las etiquetas están escritas en varias lenguas. Es decir, en la actualidad no hay única lengua dominante, como lo ha sido hasta hace pocos años el inglés, sino que esta coexiste con otras. Los estudiantes que han participado en la investigación demuestran este extremo. Todos ellos son multilingües, hacen uso de varias lenguas en sus prácticas letradas en línea.

\section{EL ORIGEN INTERTEXTUAL DE LAS VOCES EN EL DISCURSO DIGITAL}

Un discurso rara vez es homogéneo, al presentar de manera muy diversa y variable la subjetividad del enunciador. Esta multiplicidad de voces y puntos de vista presentes en cada enunciado es lo que Batjin (19341935) llama heteroglosia. Los hablantes de una lengua incorporan las declaraciones de fuentes distintas, en otros contextos, y se las apropian para adaptarlas a lo que quieren y necesitan expresar (Reyes, 1990). Calsamiglia y Tusón (2007) recuerdan que Authier en 1982 introdujo una distinción entre heterogeneidad mostrada y heterogeneidad constitutiva. Con heterogeneidad mostrada Authier explica la inserción explícita del discurso de otros en el propio discurso. Es decir, a través de la cita se incorpora un enunciado en el interior de otro indicando que se trata de palabras ajenas. Este tipo de citas pueden ser de dos tipos, de estilo directo y de estilo indirecto. 
En el caso de las citas de estilo directo hay una expresión introductoria que contiene un verbo de decir, y una cita directa marcada por guiones o comillas; siempre es la reproducción literal de un enunciado. La expresión introductoria y la cita aparecen separadas por una pausa, representada gráficamente por los dos puntos. Las citas de estilo indirecto tienen también una expresión introductoria con un verbo de decir y una cita indirecta, marcada a través de la conjunción que. La cita directa no es más verídica que la indirecta, simplemente se emplean ambas modalidades para presentar por una parte de manera diferente las representaciones del discurso del otro, y por otra la relación entre enunciaciones.

Según Authier (1982) en las citas directas el enunciador se presenta como portavoz de palabras que no son las suyas, mientras que en las citas indirectas sus palabras remiten a otro como origen de su significado. La heterogeneidad constitutiva es el discurso que está en el discurso propio (heteroglosia, intertextualidad o polifonía). Se trata de enunciados en los que el hablante parece hacer aserciones, pero no las hace, o no las hace del todo, sino que expresa el punto de vista de otra persona (Reyes, 1994). No hay señales sintácticas, deícticas o gráficas que muestren que se trata de la reproducción de palabras ajenas, y el texto se muestra como la expresión del enunciador. Si se responsabiliza de la aserción a la voz correspondiente se añade una expresión citativa: "según dice...", "para X...", "en opinión de...", etc. Si no se señala la fuente se produce una fusión entre los puntos de vista del enunciador y la proposición citada, de manera que en ocasiones es difícil discernir cuáles son las palabras del enunciador y lo que dicen los otros.

Esta heterogeneidad es importante por lo que es capaz de revelar en relación con la identidad de los autores. Primero, porque suscriben las palabras de personas en principio de más autoridad que ellos para poner de manifiesto cómo se sienten, lo que piensan, etc. Segundo, porque al hacerlo así se posicionan de manera simbólica con esas mismas personas en lugar de hacerlo en un grupo social abstracto (Ivanic, 1998).

Las muestras más explícitas de heterogeneidad en los estudiantes que participaron en la investigación se encontraron en aquellos lugares en los que representaron gráficamente a través de las comillas, o atribuyeron explícitamente lo que escribieron como la voz de otra persona. En el primer apartado nos centraremos en analizar aquellas citas o paráfrasis de otros autores que siguen las convenciones habituales de atribución, para mostrar en qué medida aparece o no la voz del autor en la cita. En la segunda parte se tratarán los textos en los que los estudiantes emplearon las palabras de otros sin atribución. En cualquier caso, los dos ejemplos ofrecen una imagen 
interesante de la relación entre su propia voz como autores y la voz hacia la que dirigen la mirada.

\subsection{Citas directas}

Tradicionalmente se ha establecido una distinción entre citas y paráfrasis. Con las citas los autores traen no solo las ideas sino el estilo discursivo a sus propios textos, aunque en el contexto de mi tesis creo conveniente extender esta influencia al timeline o perfil en su conjunto. Como Androutsopoulos (2010) sugiere los usuarios de redes sociales son una especie de operadores intertextuales, que editan materiales multimodal y multimedia en distintas plataformas y con diferentes propósitos. Es decir, las entradas analizadas no pueden ser tomadas como un género escrito, sino como un híbrido de rasgos genéricos que podemos identificar en los distintos textos (Lee, 2011, 2017).

Los participantes generalmente comparten citas de determinadas características, capaces de articular su discurso en determinados momentos. Por ejemplo, en el caso de tres estudiantes italianas (Giusy, Melania y Fabiola) cuyo discurso en español en Facebook e Instagram se caracteriza por el uso extensivo de citas y cuyos textos servirán para mostrar este uso en este apartado, comparten contenido de características similares, aunque con finalidades diferentes. Suelen compartir refranes en español, citas tomadas de obras literarias, versos tomados de canciones, frases "motivacionales" y, por último, imágenes cita. Comenzaremos explicando, por el peso que tienen respecto al resto de mensajes, el uso de los refranes. Para Giusy, su uso está relacionado tanto con el mensaje que representan como con la musicalidad.

No te pongas así! Tampoco tienes que ahogarte en un vaso de agua ante cualquier problema Valeria

(Giusy, 4 de junio de 2015, Facebook)

En este caso hay una ligera modificación sobre el refrán original, una personalización que le sirve para decirle a una amiga que relativice un "fracaso" académico (había suspendido un examen de español) porque no es un problema importante. No es el primero que emplea para enviar mensajes en Facebook a alguna de sus amigas, como este que dirige a Melania en su propio timeline el 2 de junio de 2014. 
Lo que sea sonará Melania

De la misma manera, Melania emplea en ocasiones refranes que modifica para conformarlos a lo que necesita expresar, y aludir, de forma más o menos velada, a su estado de ánimo. Se muestran a continuación varios ejemplos de este uso.

En el primer ejemplo, compartido en su timeline de Facebook el 20 de marzo de 2014, junto al uso del refrán Melania emplea uno de los recursos de la plataforma para mostrar su descontento y estado de ánimo en relación a algún evento (se siente + emoji). De esta forma, solo los receptores que mantengan con ella una relación de más confianza o intimidad podrán saber exactamente de qué se trata. Para el resto, por el contrario, aunque es evidente que se trata de la expresión de su malestar es tarea imposible vincularlo a algún hecho concreto.

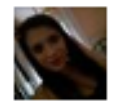

Melania Debole : : se siente molesta.

20 de marzo de 2014 .

\section{Guerra avisada, no mata gente!}

En el segundo ejemplo, compartido el 3 de junio de 2014, la expresión del estado de ánimo se vehicula de nuevo a través del uso de un refrán, y el apoyo gráfico se realiza a través de distintos signos ortográficos, dos guiones y un punto.

cría cuervos y te sacarán los ojos!!-.-

Por último, esta entrada compartida el de abril de 2014, en la que articula la expresión de sus sentimientos a través de procedimientos diferentes a los anteriores. Por una parte el uso del refrán que se resalta en mayúsculas para amplificar su poder de convicción; por otra el uso de una oración valorativa que se inicia con un signo de exclamación.

¡Qué asco me da la gente falsa, GUERRA AVISADA NO MATA GENTE!

En los tres casos aparecen sin entrecomillar, aunque cualquiera familiarizado con la lengua y la cultura hispana es capaz de percibir que se trata de refranes convenientemente utilizados para hacer partícipes a los 
demás de un malestar inespecífico, porque aunque Melania en el tercero se refiere a la gente falsa no da más indicaciones acerca de lo que le ha podido suceder. Melania se posiciona a sí misma no solo junto a las ideas y mensajes que transmiten estas frases populares, sino al lado de una determinada comunidad de práctica, la de estudiantes de español como ella. En ese sentido, la comunidad del español es también la comunidad imaginada a la que aspira poder pertenecer Melania, especialmente si entendemos que esta es la que le ofrece posibilidades de alcanzar en el futuro diferentes representaciones mejoradas de su identidad.

Melania: Me afectaron esas frases cuando las estudié en la universidad. Sabía que todo el mundo no comprendía, sólo lo hacía(n) la gente que hablaba español. Las utilicé porque estaba orgullosa de conocer los refranes y porque me (afectaba) el significado.

Hay ocasiones en las que las estudiantes omiten las señales tipográficas que indican citación, aunque los lectores pueden identificar fácilmente los textos o eventos de habla a los que hacen referencia. Fabiola comparte tres veces diferentes versos de la canción Hasta la raíz, de la cantante mexicana Natalia Lafourcade, en su timeline de Facebook. De las tres veces que se apropia de fragmentos de la canción, solo una de ellas aparece el entrecomillado, aunque reconoce que no sigue ningún criterio concreto por el que muchas veces emplea las comillas y otras no. El reconocimiento en cualquier caso del resto de versos es sencillo cuando tienes en cuenta el conjunto de textos, enlaces, fotografías, etc., que comparte en su perfil.

En la primera entrada el texto está constituido por el título de la canción, entrecomillado y seguido de un emoji.

"Yo te llevo dentro"

(Fabiola, 26 de abril de 2015, Facebook)

En esta segunda entrada el texto incluye algunos elementos más: Fabiola incluye algunos versos de la misma canción, a los que añade el enlace de la canción a través de Youtube. 


\section{Fabiola Motta

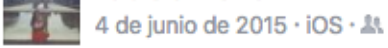

Una tarde suba una alta loma mire el pasado sabrás que no te he olvidado.. Yo te llevo dentro hasta la raíz..

Y por más que crezca vas a estar aquí

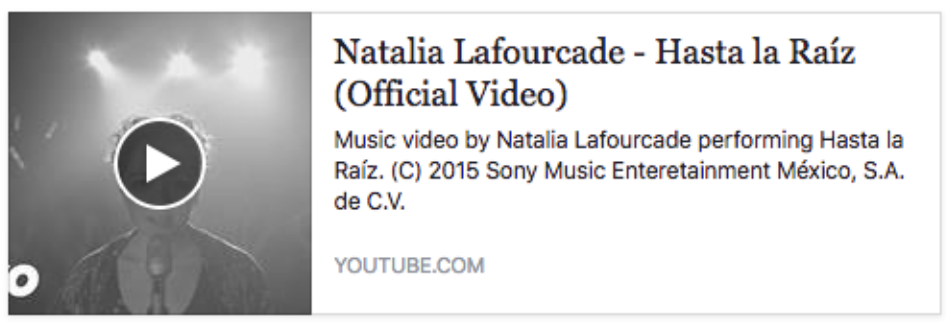

I. Me gusta $\quad \Rightarrow$ Comentar $\Rightarrow$ Compartir

No es la única estudiante que emplea versos de canciones en español, acompañadas o no del enlace del vídeo correspondiente. Melania, en una entrada similar a estas, comparte un vídeo de Enrique Iglesias y en la entrada principal algunos de los versos de la canción.

Yo te miro, se me corta la respiración

Cuanto tu me miras se me sube el corazón

(...)

$Y$ en silencio tu mirada dice mil palabras

La noche en la que te suplico que no salga el sol

(...)Tu cuerpo y el mio llenando el vacío

Subiendo y bajando

Ese fuego por dentro me esta enloqueciendo

Me va saturando

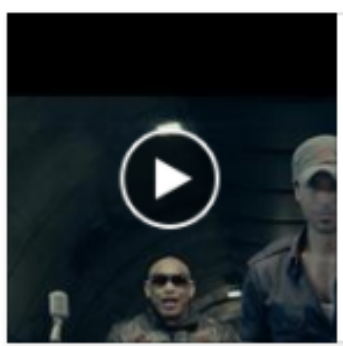

Enrique Iglesias - Bailando (Español)

$\mathrm{ft}$. Descemer Bueno, Gente De Zona

Enrique Iglesias wants to see you dance! Make a video

inspired by his song "Bailando" (the English OR

Spanish) versions and you could win tickets and get

the...

YOUTUBE.COM

En este ejemplo, la identificación del texto con los autores originales, al estar acompañada del enlace del vídeo, facilita el reconocimiento. En ambos textos, tanto Fabiola como Melania, deciden establecer su identidad posicionándose junto a los autores a quienes citan, sin mostrar fisuras o 
contradicciones: si los reutilizan, asumiendo lo que se dice, es porque asumen como propio el significado, pero también por el deseo de identificarse con los autores de quienes han tomado las características discursivas (Ivanic, 1998). Este deseo puede estar motivado por admiración hacia esas personas concretas, o por la necesidad de conformarse a los valores, gustos e intereses de la cultura dominante.

Las relaciones sociales alrededor de un texto pueden contribuir también a la construcción social de la identidad, en este caso respecto a la recepción de sus lectores. Esto es especialmente relevante para los estudiantes de lenguas extranjeras. Uno de los temores más recurrentes manifestados durante las entrevistas era cometer errores, que los demás pudieran percibir que su español no era el correcto, y también que no se entendiera lo que realmente querían expresar. Su dificultad es doble: por un lado, comunicarse con éxito en una lengua que no es la suya y, por otro, representarse a sí mismos con fidelidad en lo que escriben y comparten. En ocasiones era fácil advertir en las entrevistas y análisis de sus textos las resistencias de algunos participantes a acomodarse a las exigencias y expectativas ideológicas de la comunidad discursiva dominante. Otros estudiantes, sin embargo, parecen amoldarse de manera clara a los deseos y exigencias de los grupos sociales a los que aspiran a pertenecer. Es decir, las interacciones sociales inciden en la auto representación en la escritura, e identificar los procesos mediante los que llegan a identificarse con sus textos, propios o no, ha llevado a contar con su perspectiva para contextualizarlos.

Durante las entrevistas la mayor parte de los estudiantes manifestaron que su intención cuando escribían era poder comunicarse con los demás siendo ellos mismos, sin pensar en quiénes les podían leer o de qué manera se proyectaba su imagen. Es interesante que la identidad que Fabiola, Melania y Giusy quieren hacer reconocible cuando emplean el español, fundamentalmente en Facebook, está relacionada con alusiones o citas directas de textos ajenos. Todos los discursos presentan al menos dos voces (Ivanic, 1998), y una de ellas es la del hablante o escritor. Cuando ellas deciden adoptar el papel de animadoras eligiendo citas que preservan las palabras del autor o autores originales, dan la impresión de estar posicionadas junto a los valores, creencias y prácticas que asociamos con la voz original. Gran parte de su identidad relacionada con la escritura en español está construida discursivamente, pero ellas tienen la impresión de que a través de lo que escriben muestran su verdadero yo. Para Giusy el verdadero yo que muestra cuando escribe o comparte citas en español en 
Facebook tiene que ver con la coherencia que desea que exista entre lo que expone de manera pública y su comportamiento.

Giusy: No, en español escribo cosas que se refieren a mi estado de ánimo. Es curioso. (...) Para mí es fácil expresar lo que realmente siento en español y ese tipo de cosa(s) prefiero escribirla(s) en español. Soy una persona muy tímida y muchas veces cuando escribo en Facebook prefiero escribirlo en español, quizás porque muchos de mis amigos no lo entienden y así puedo proteger mis sentimientos. (...) Para mí es importante ser coherente. Es decir que lo que digo en las redes sociales es lo mismo en la vida. Si no me gusta algo lo mismo es en la realidad.

Giusy demuestra que tiene conciencia de las identidades construidas discursivamente que adopta en español. Se ha adueñado de su discurso apropiándose no solo del contenido proposicional de los textos que comparte, sino de la posición ideológica que estos manifiestan. En su caso, la representación de sí misma viene dada por las elecciones del tipo de textos o autores a los que da cabida en su timeline de Facebook. En este sentido, hay una serie de citas muy particulares bastante frecuentes por parte de Giusy y también Fabiola. Se trata de una serie de citas tomadas de distintas páginas de Facebook, que en general aparecen sobreimpresas en una imagen. Son citas de muy distintos tipos y procedencias, que ellas emplean para señalar que el contenido proposicional que se comparte se asume como propio, sin mediar ninguna modificación, pues se encargan únicamente de su distribución. Hay imágenes-cita encaminadas a señalar algún rasgo de conducta reprobable en los demás, como en esta que Fabiola comparte desde una página de Facebook dedicada a la literatura, el 21 de octubre de 2015.

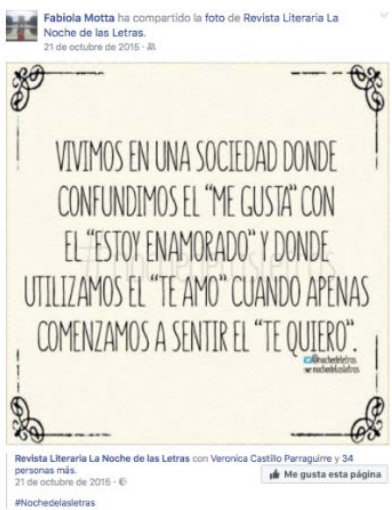


O esta otra compartida por Giusy el 9 de septiembre de 2014 con la misma intención, señalar algún tipo de comportamiento como no adecuado o reprobable, a través de un tipo de cita un poco especial. No se trata en estos casos de copiar o transcribir simplemente las palabras o voces ajenas, sino que el contenido de ese mensaje se asume como propio y se transmite y distribuye sin modificaciones o alteraciones por su parte.

Giusy Naselli ha compartido la foto de Revista Literaria La Noche

de las Letras.

9 de septiembre de 2014 . 1 .

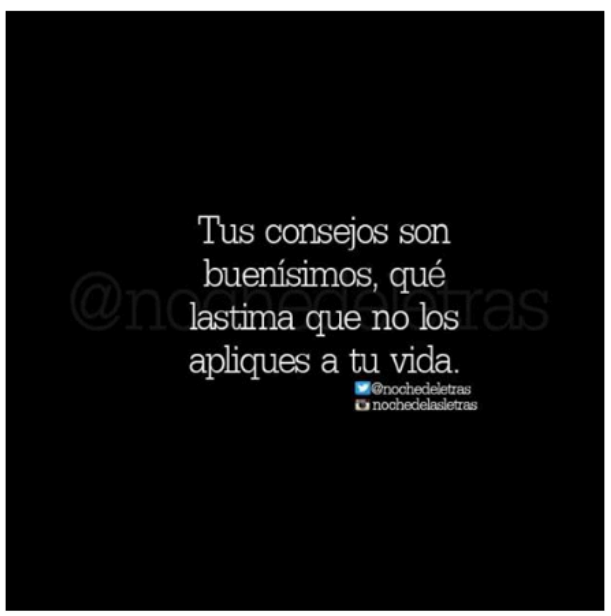

El objetivo de este tipo de imágenes citas es tanto la transmisión de un mensaje como informarnos de sus pensamientos y estado de ánimo, valiéndose de una estructura explícita de discurso directo, de manera que al dar cuenta de su origen resguardan sus sentimientos. Es más fácil esconderse detrás de los enunciados a la hora de hacer determinadas aserciones, porque revelan junto a su pensamiento una voz ajena, haciendo difícil distinguir qué es lo dicen ellas y en qué medida se hacen responsables de lo que están expresando.

\subsection{Citas que no parecen citas}

Las ocasiones en las que se apropian de un sistema conceptual ajeno sin que medie ningún tipo de elemento que sirva para marcar que están repitiendo o apropiándose de las palabras de otros son también abundantes. 
En ocasiones esas apropiaciones no se ajustan a ningún sistema, sino que son invenciones creadas ad hoc para transmitir ideas o valores asociados a fuertes sentimientos por parte de los estudiantes (Krees y Leween, 2001). Así, un signo que tiene un significado en un lugar concreto, un grupo social, o una cultura, se asocia con los valores o temas con los que quieren dotar a su propio discurso. Por ejemplo, cuando Elena cuelga una imagen en su cuenta de Instagram del Palacio de Cristal del Parque del Retiro con el texto Algunos días tienen un color especial, cualquier lector familiarizado con la cultura popular española no podrá evitar relacionarlo con el título y la letra de una famosa canción sobre Sevilla ("Sevilla tiene un color especial").

Estos casos son relativamente frecuentes, pues hay determinadas palabras (tequila, sangría, fiesta), canciones ("Living la vida loca"...), conceptos (siesta), etc., que están no solo lo suficientemente globalizados como para ser entendidos por una amplia mayoría de usuarios, sino que además remiten a realidades culturales concretas.

Melania, en una entrada de Facebook compartida el 22 de octubre de 2014, por ejemplo, hace referencia a una noche de estudios.

Perdóname madre por mi vida loca-.- \#sofuckin'pissedoff

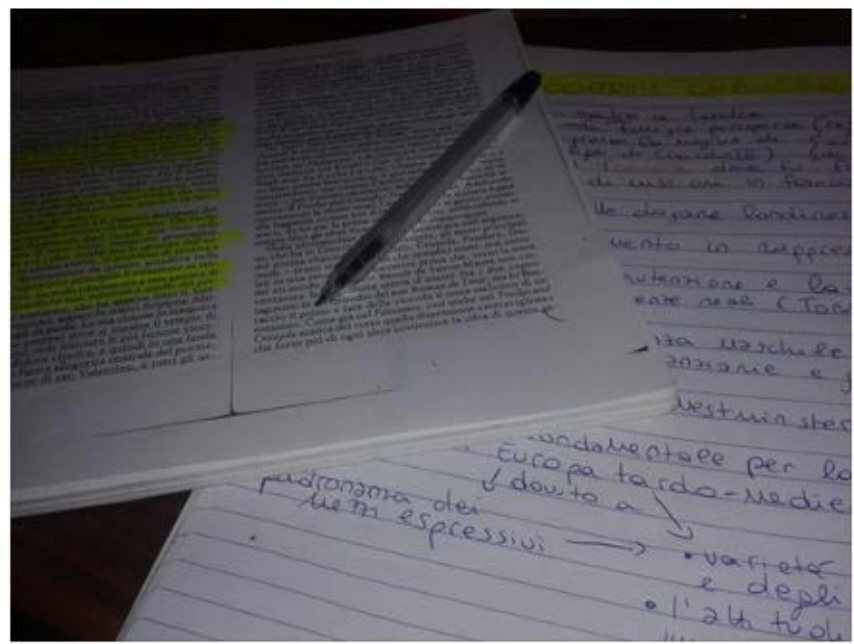

Es precisamente gracias a la imagen que podemos entender de manera clara a qué se refiere exactamente con mi vida loca y por qué está tan enfadada (la etiqueta en inglés -.-\#sofuckin'pissedoff). 
Amalie, por su parte, tiene varias referencias similares en su cuenta de Instagram en febrero y marzo de 2015, en textos generalmente escritos en inglés, aunque complementados con algunas etiquetas en español. El primero de estos ejemplos le sirve de introducción (lo escribe en febrero de 2015, nada más empezar su periodo de estudiante Erasmus en Madrid) a la vida madrileña, esa vida de ocio y diversión a la que hace referencia en bastantes ocasiones en sus textos.

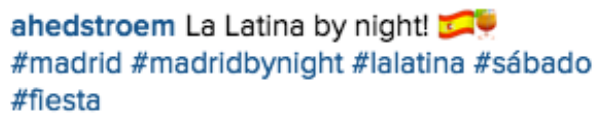

(Amalie, 22 de febrero de 2015, Instagram)

El segundo, forma parte de una serie de textos en los que describe el tipo de vida y las actividades que lleva a cabo en este periodo. En este caso, con una de sus amigas y compañeras de universidad, a la que menciona a través de un doble procedimiento: la imagen en la que ambas aparecen juntos; la mención con @cuenta.

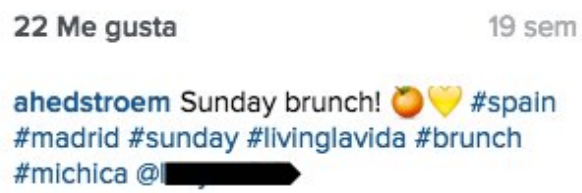

(Amalie, 1 de marzo de 2015, Instagram)

O la más curiosa, en la que hace un juego de palabras con una palabra en español y el título de una canción en inglés bastante popular, Bootylicious.

ahedstroem Mi chicalicias $\theta$ \#biffehygge

\#chiquita \#fredagidejligselskab \#kærlighed

(Amalie, 7 de noviembre de 2014) 


\section{COMUNIDADES DE PRÁCTICA Y COMUNIDADES IMAGINADAS}

Redes sociales como Facebook e Instagram han propiciado un nueva manera no solo de comunicarnos, sino de relacionarnos con los demás, al permitir interacciones con personas con las que el grado de cercanía es muy tenue y en muchas ocasiones inexistente; en espacios públicos o semipúblicos; y no solo en nuestra primera lengua, sino en lenguas diferentes. Las identidades están en flujo constante, como consecuencia por una parte de la participación en nuevos discursos y las posibilidades de formar parte de diferentes comunidades de práctica a través de redes sociales que funcionan como comunidades de práctica difusas. Para Melania que durante su etapa universitaria consideró continuar con el español por la importancia creciente de esta lengua en las escuelas italianas, es decir, como una posibilidad laboral más, el aprendizaje de la lengua implica también la construcción de su(s) identidad(es) en esa misma lengua. De la misma manera, la motivación para aprender el español tiene efectos sobre su participación en Facebook e Instagram. Emplea Facebook para comunicarse en español con estudiantes de español como lengua extranjera de origen italiano o de otras procedencias.

con mi hermanito vamos siempre a tomar algo! Somos gorditos:) Jer (Melania, 17 de diciembre de 2013, Facebook)

En una conversación anterior con el mismo amigo, iniciada por la actualización de estado de Melania en italiano, los comentarios entre ambos se escriben de nuevo en español. 
Influenza! Ti O DIO!

Ver traducción

Me gusta Comentar $\rightarrow$ Compartir

13

Ver 13 comentarios más

pobresita :(l

12 de octubre de 2013 a las 13:11 - Me gusta · Compartir · D

Melania Debole No puede ser! Siempre, tengo gripe 6

12 de octubre de 2013 a las 13:13 - Me gusta - Compartir

que te mejores hermanita :

12 de octubre de 2013 a las 13:14 · Me gusta · Compartir

Melania Debole $\cdot$ Muchas gracias Hermanito

12 de octubre de 2013 a las 13:16 - Me gusta - Compartir

(Melania, 11 de octubre de 2013, Facebook)

Por otra parte, su participación es el reflejo de cómo las interacciones en Facebook y especialmente la aceptación por parte de otros usuarios tienen un efecto positivo en relación a su motivación para aprender. Es posible interpretar el posicionamiento de Melania a través de la teoría del aprendizaje situado de Lave y Wenger (1991) en relación con dos aspectos: el primero se refiere al resto de miembros participantes de una práctica sociocultural específica; el segundo, a su sentido de identidad como alumna aventajada (master practitioner). El conocimiento de la lengua es importante, pero aún lo es más el valor que tanto ella como otros amigos depositan en el hecho de pertenecer a determinadas comunidades.

Se entiende también desde el marco de esta teoría de la práctica social esta interacción en la que Melania comparte en su timeline de Facebook el 5 de abril de 2014 la imagen del resultado de la prueba de nivel en línea del Instituto Cervantes, a través de la que los estudiantes obtienen su nivel de español. En su caso, le recomiendan llevar a cabo los niveles C1.1, C1.2, y una de las amigas españolas con las que suele compartir conversaciones en Facebook vuelve a repetirle que su nivel de español es muy alto y que puede venir a España sin problemas. 


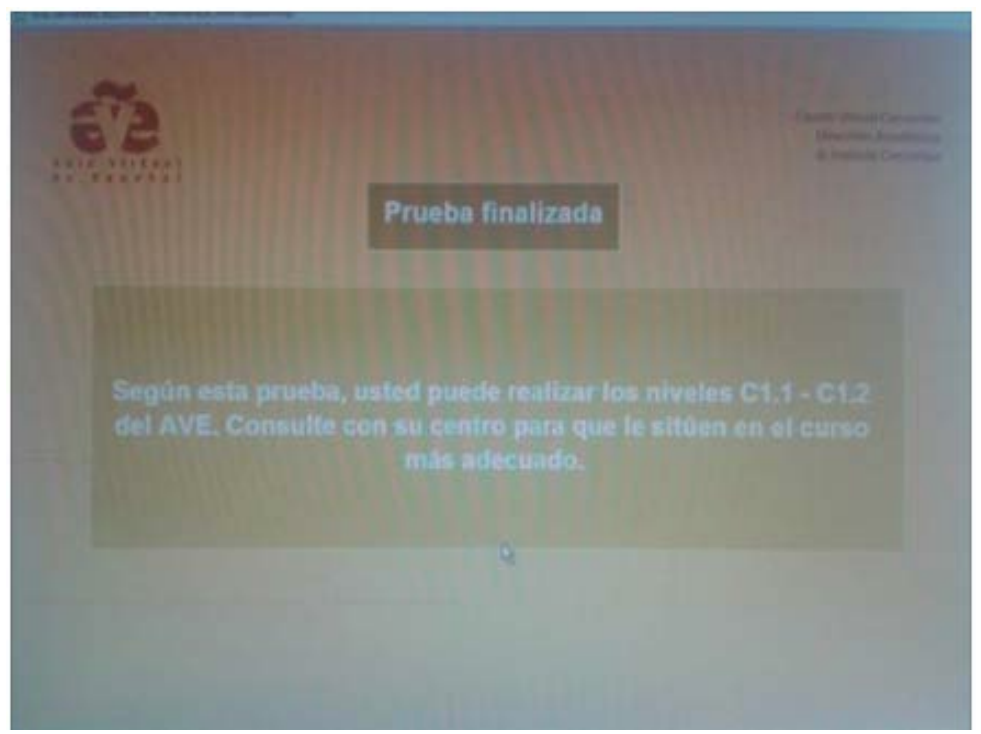

Esta es la interacción que se produce entre ambas amigas a partir de esa imagen.

Thais: "Enhorabuena guapa! Ya puedes venir a España sin problema y así perfeccionas el idioma, recuerda que te dije que hablabas muy bien español ahahah un abrazo, espero verte pronto linda

Melania:" ¡Te echo de menos! Quiero ir a España para aprender más el idioma pero tu tienes que aprender más el italiano..y por eso..quero que tú vuelvas a Catania

La noción de comunidades imaginadas de Norton (2000) puede también ayudar a explicar este proceso de construcción de la identidad de Melania. La idea de vinculación (alignment en el original) es central, puesto que los aprendientes hacen todo lo necesario para poder participar en una comunidad más grande. El concepto de imaginación de Norton, como ella misma recuerda, remite a Wenger (1998:176).

My use of the concept of imagination refers to a process of expanding our self by trascending our time and space and creating new images of the world and ourselves. Imagination in this sense is looking at an apple seed and seeing a tree. 
Cuando Melania conversa en español en línea con otros amigos y compañeros de estudios, el campo de acción sobre el que realmente opera es la comunidad extendida del mundo, que se desarrolla en el ámbito de distintas redes sociales o plataformas de aprendizaje en línea (Italki, por ejemplo). Es la comunidad que ella ha imaginado, compuesta por nativos y no nativos, el lugar donde puede organizar continuamente el sentido de quién es y cuál es su relación con el grupo o grupos sociales en los que desea participar e integrarse. De esta manera, ella reconoce cuál es el papel que algunas de sus amigas españolas tienen en su aprendizaje y en sus éxitos académicos. Es también a quienes responsabiliza y agradece a través de una mención indirecta ("mis amigas españolas") el hecho de haber aprobado la asignatura de español en la universidad.

Este domingo tengo que dar gracias a mis amigas españolas, ellas son las que me ayudaron a mejorar mi español !! ESPAñOL 2 APROBADOO!

(Melania, 22 de junio de 2014, Facebook)

El perfil de Giusy y Fabiola académicamente hablando es muy similar al de Melania, aunque las tres emplean Facebook e Instagram con propósitos comunicativos diferentes. Es precisamente el hecho de estudiar lenguas y ser estudiantes de español en particular uno de los rasgos que llaman la atención cuando te enfrentas al análisis de sus perfiles y cuentas de Facebook e Instagram. Hay una intención evidente en todas ellas de mostrar a los amigos y usuarios que no hablan español qué es lo que les diferencia de ellos.

Cuando Giusy comenta que escribe en español y no en italiano sobre determinados aspectos de su vida para proteger sus sentimientos, no hace sino poner de manifiesto que aspectos concretos que comparte de manera pública en su perfil de Facebook, en realidad solo pueden ser interpretados de manera correcta por aquellos que o bien estudian la lengua, como ella, o bien son hablantes nativos de la misma. De la misma manera es posible interpretar una serie de citas literarias que en la mayor parte de las ocasiones hacen referencia directa a las lecturas obligatorias en la universidad.

En el caso de Fabiola la mayor parte de entradas relacionadas con sus estudios y lecturas en español se comparten a través de Instagram y no de Facebook. Instagram es un medio más controlado, en la medida en que tiene su cuenta configurada como privada. Sus entradas, por otra parte, son 
bastante más personales e íntimas de las que suele compartir en Facebook. En ese sentido, predominan las imágenes en las que aparece en solitario, generalmente en un plano medio o primer plano, mientras que en Facebook las imágenes grupales son mayoritarias. Se percibe un intento de construir su identidad de manera diferente: resaltando sus valores individuales en Instagram, y orientada hacia sus diferentes grupos de amigos en Facebook. De esta manera, comparte una imagen de sí misma con la ciudad de Toledo al fondo acompañándola de una cita de Pablo Neruda, en la que alude a la especial orografía de la ciudad, construida en lo alto de una montaña.

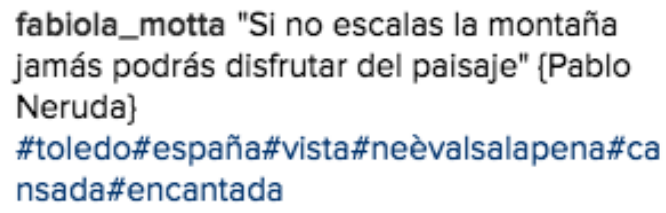

(Fabiola, verano de 2016, Instagram)

Poco antes había colgado una imagen de sí misma con la estatua de Cervantes, en Toledo también.

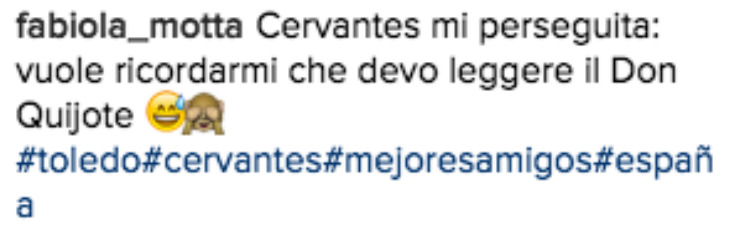

(Fabiola, verano de 2016, Instagram)

Las etiquetas son en este caso las que proporcionan en español información extra acerca del lugar en el que se encuentra (\#toledo, \#españa) y la importancia de la figura con la que aparece en la fotografía (\#cervantes, \#mejoresamigos). Zhao, Grasmuck y Martin (2008) señalan cómo es habitual en las páginas de citas que los usuarios decidan mostrar antes que contar, probablemente porque son medios que privilegian un posicionamiento personal más pasivo. Instagram no está diseñada específicamente para buscar pareja(s), pero sí comparte con ese tipo de páginas la posibilidad de generar conexiones fuera del ámbito de las relaciones de amigos y conocidos (gente a la que efectivamente conoces o amigos de amigos). La anonimia propicia una suerte de representación de la identidad resultado de un entorno social muy determinado, que en este caso 
pone en evidencia tanto el yo real o verdadero de Fabiola, como sus deseos de los yoes posibles. Fabiola es en el momento de la investigación una estudiante de lenguas extranjeras y sus literaturas y las culturas a las que representan, a la que le interesa dar esa impresión de sí misma, a través de las elecciones lingüísticas, las etiquetas, los emoticonos y, por último, sus propias fotografías.

En Facebook, comparte una imagen similar días antes, imagen que le sirve durante días como imagen de portada en esa red. En la misma aparece de nuevo Fabiola junto a la estatua de Sancho Panza y Don Quijote, al que confunde o identifica con el autor de la obra, Cervantes. Es una de las pocas veces que aparece en una imagen en solitario en esta red social, porque como he mencionado antes lo normal es que se muestre como otra integrante más del grupo o de los grupos, porque no siempre son los mismos, de los que forma parte. El texto que acompaña a la imagen es el siguiente.

Mis nuevos amigos españoles: Sancho Panza y Miguel de Cervantes (Fabiola, 25 de julio de 2016, Facebook)

Son llamativos también en el caso de Fabiola los ejemplos en los que emplea citas de autores extranjeros traducidas al español. Como en este caso, en la cita que reproduce en español los versos de un poeta bangladesí, Kalwar, que suele escribir en inglés.

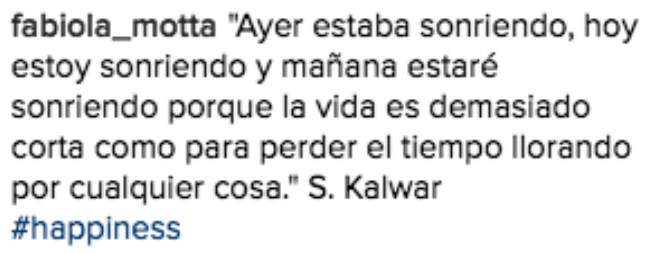

(Fabiola, febrero de 2015, Instagram)

Ivanic (1998) relaciona el concepto central de la teoría vigokstkyana sobre el desarrollo de los recursos intramentales que proceden de la vida social, con la idea de intertextualidad de Wertsch. Para Wertsch (1991) las personas suelen manifestar en sus elecciones de significados patrones socialmente determinados, que no están al alcance de todos. El acceso a este tipo de discursos específicos viene por tanto determinado por una serie de 
circunstancias sociales, como la educación que han recibido, o las redes sociales e interpersonales de las que forman parte. En este sentido, la trayectoria vital de Fabiola, su yo autobiográfico, tiene un papel fundamental en lo que escribe. Este yo autobiográfico está conformado por sus intereses, ideas, opiniones, voces a las que ha decidido dar cabida en lo que escribe, sentimiento de valía personal (sense of selfworth) y prácticas letradas (Ivanic, 1998). En relación a su sentido de valía personal, el sentido del estatus en el que se encuentra respecto a los demás, es posible relacionarlo no solo con sus pasadas experiencias, sino con el tipo de identidad personal que está creando sobre sí misma. El acceso por tanto a discursos y los posicionamientos a los que se asocian, como los que vemos en estos dos ejemplos, son producto de su educación universitaria y entorno social.

Ejemplos similares los encontramos también en los timeline de Facebook de Giusy y Melania. Con frecuencia, como se mencionaba antes, señalando lecturas de algunos de sus cursos en la universidad, como en el caso de la novela de Marcela Serrano Diez mujeres, de la que tanto Giusy como Fabiola han compartido algún fragmento en Facebook (Giusy) y en Instagram (Fabiola).

"Ni puños ni gritos: la gente no cambia. Hay que aprender eso desde el primer día y no gastar años, penas y fatigas tratando de lograrlo. Y si Dios creó algo de flexibilidad en el mundo, se la acapararon las mujeres." ${ }^{2}$

(Giusy, 13 de septiembre de 2015, Facebook)

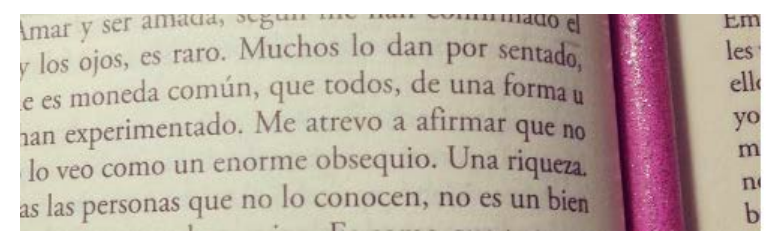

fabiola_motta "Nada es ramplón si fuiste millonaria. Algo así es el amor. [...] Lo que había sentido me transformaba, eso era inamovible" (Diez Mujeres\}

\#book\#romance\#español\#diezmujeres\#ex am\#university

(Fabiola, noviembre de 2015, Instagram)

En otras ocasiones son algo más concretas y señalan a través de la aplicación de Facebook cuál es el libro que están leyendo ${ }^{3}$. Este tipo de

\footnotetext{
${ }^{2}$ La cita es entrecomillada por Giusy, aunque no mencione quién es la autora de la misma.

${ }^{3}$ Hay una opción utilizada por bastantes usuarios en Facebook en la que es posible señalar "qué estoy leyendo en este momento"
} 
actualizaciones son una respuesta directa al mensaje original de Facebook en el que se pregunta a los usuarios qué estás haciendo o, como en este caso, qué estás leyendo. De esta manera los mensajes de este tipo están limitados por las prestaciones tecnológicas de Facebook. Por ejemplo, aparecerá el nombre del usuario, seguido del emoticono de un libro, y el verbo estar más un gerundio para marcar que es la actividad que está llevando a cabo en ese momento.

En la entrada, por otra parte, también se muestra la imagen del libro que se está leyendo y el número de usuarios a los que les gusta, de manera que es posible 1) mostrar los gustos y aficiones ante los propios amigos y contactos; 2) formar parte de una comunidad de usuarios más amplia, que comparten similares gustos y aficiones.

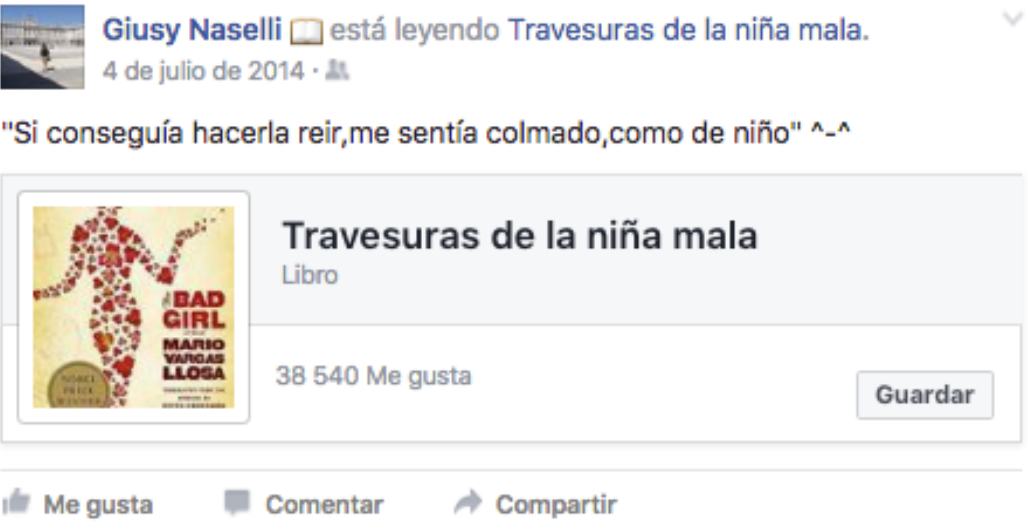

(Giusy, 4 de julio de 2014, Facebook)

La aportación principal de Giusy en esta actualización es la selección de una de las citas del libro junto al emoticono $\wedge$ _ , para corroborar o mostrar su acuerdo con lo que acaba de compartir.

En estos ejemplos de citas literarias el objetivo es la fiabilidad y, sobre todo, la autoridad, y por eso se emplean marcas gráficas que muestran el fragmento citado, junto con la atribución clara de la autoría. En relación a esto es interesante observar cómo por una parte la intención de Fabiola, Giusy y Melania es posicionarse con los textos que escriben y comparten como miembros de una comunidad de práctica: son estudiantes de lenguas que escriben en sus redes sociales en su lengua materna y en el resto de lenguas que estudian y aprenden, español e inglés. Su presencia como autoras se limita a establecer sus puntos de vista, sus ideas o intereses a través de las palabras de figuras de mayor autoridad, exonerándose de esa 
forma de asumir la responsabilidad total de la versión de ellas mismas que se percibe en los textos señalados.

En otros casos, sin embargo, las alteraciones que se hacen de los textos originales suponen la voluntad de mantener no solo la palabra original, sino la intencionalidad del autor del discurso citado. Hay distancia entre el enunciador y la proposición que reproduce, pero se apropian del discurso, del sistema conceptual del autor, para mostrar que se asume como propio. Como en este cita de Giusy de los versos de uno de los poemas más famosos de Bécquer, que dirige a una de sus amigas de Facebook, el 26 de junio de 2012.

¿Qué es poesía?, dices mientras clavas

en mi pupila tu pupila azul.

¡Que es poesía!, Y tú me lo preguntas?

Poesía... eres tú.... te la ricordi $\because$ il nostro amato Becquer $\mathcal{*}^{*}$ Alessia

O la traducción que hace Melania del español al italiano de un fragmento de Galeano, de una cita que encuentra en una página de Facebook. Como le gusta, decide compartirla en español y traducirla al italiano para que pudieran entenderla también los amigos y contactos italianos que no leen en español.

"Hay un único lugar donde ayer y hoy se encuentran y se reconoces y se abrazan. Ese lugar es mañana" (C'é un unico luogo in cui oggi e ieri si incontrano, si riconoscono e si abbracciano. Questo luogo é la mattina.) Eduardo Galeano

(Melania, 7 de octubre de 2013, Facebook)

\section{VISIÓN SOCIAL DE LA ESCRITURA EN LÍNEA}

Uno de los factores esenciales en el desarrollo tanto de la competencia escrita en una lengua, como de la literacidad, es la participación en actividades sociales que requieran el uso de la misma. En este sentido, no hay muchas diferencias entre aprender una lengua nueva y hacerse consciente del tipo de prácticas letradas relacionadas con un nuevo contexto cultural. Las prácticas letradas están conformadas de acuerdo a diferentes propósitos sociales, y su composición depende del entorno social al que pertenecen o en el que fueron creadas. Cuando escribimos no solo hacemos 
uso de las prácticas letradas y discursos a los que hemos estado expuestos, sino que los reproducimos o recreamos tomando en consideración nuestros propios intereses y propósitos. Ser letrado, en definitiva, tiene implicaciones sobre la identidad.

De esta manera, Ivanic (1998) señala cuatro de los aspectos que debemos tener en consideración cuando hablamos de la identidad de los autores. En primer lugar, el yo autobiográfico (autobiographical self), que hace referencia al origen, a la historia personal del autor. En segundo lugar, el yo discursivo (discoursal self), que está relacionado con la manera en la que consciente o inconscientemente un autor pretende transmitir sus valores o creencias en un determinado escrito. En tercer lugar, el yo como autor (self as author), término que refleja cómo se presentan sus ideas, creencias, opiniones en los textos escritos. Así, pueden elegir esconderse tras las opiniones o ideas de otras personas, diluyendo su propia responsabilidad sobre lo que escriben o, por el contrario, pueden presentar lo que escriben como su verdad, responsabilizándose y posicionándose de manera clara en sus textos. En último lugar, hace referencia a las posibilidades para la expresión de la individualidad (possibilities for selfhood), relacionando la identidad individual de los autores con las posibilidades de individualidad o autoexpresión disponibles en el contexto social o institucional del que forman o quieren llegar a formar parte.

Desde esta perspectiva, las elecciones que se toman respecto a las convenciones lingüísticas, las reglas o prácticas de una determinada cultura o sociedad tienen un reflejo directo en la relación que se establece entre literacidad e identidad. Se puede tomar una posición de subordinación respecto a los otros dentro de un Discurso, de manera que se asume un papel social que, aunque ajeno, sirve para anunciar qué forma de auto identificación estamos empleando (Gee, 1990). O dicho de otra manera, son autores (en el original estudiantes) colonizados por el Discurso, incapaces de mostrar adecuadamente una manera de estar e interactuar en el mundo aceptable y reconocible por los otros miembros de ese grupo social. Esta caracterización es especialmente relevante cuando pensamos en las personas que suponen el foco de interés de mi investigación: estudiantes extranjeros de español que se comunican con mayor o menor frecuencia en esta lengua en redes sociales.

En este apartado se mostrará la posición que adoptan frente a la comunidad discursiva dominante algunos de los participantes en la investigación: si aceptan sin reticencias el papel de estudiantes colonizados (colonized insiders) o, por el contrario, se rechazan abiertamente y sin 
ambages tanto los límites discursivos impuestos, como la forma en la que los otros han decidido posicionarles (colonized outsiders). Se señala, además, una tercera opción, la que es más general por otra parte: la de aceptar en ocasiones ser presentados de diferentes formas, adaptando o renegociando sus identidades en función de la situación o del momento de su vida.

La siguiente entrada que Somin, estudiante coreana de Arquitectura de la Universidad Politécnica de Madrid en el momento de la investigación, comparte en Facebook el 21 de abril de 2015, es un claro ejemplo de cómo muestra sentimientos ambivalentes hacia la identidad que proyecta en sus textos respecto a la comunidad discursiva representada por los españoles.

\section{Orgullo españa viva español}

Ahora conozco muy muy bien todas las calles de Comunidad de Madrid donde están los pùuus ministerios de educación. Ah, las consejerias también. Me encanta la situación. Qué feliz!

A pesar de alguna confusión con el uso de las combinaciones léxicas más habituales entre España y español (orgullo español; viva España), es evidente el uso del sarcasmo en este texto. De hecho, lo que más llama la atención es que haya decidido presentar de esta forma una característica generalmente utilizada por los propios españoles como algo positivo. A diferencia de los textos de otros estudiantes, que de manera explícita evitan expresarse con negatividad y enfado, Somin no rehúye transmitir ni sus sentimientos ni sus opiniones, aunque el hacerlo la pueda colocar en una situación compleja respecto a los posibles receptores de su texto. La expresión "pùuus", en lugar de la palabra "putos", para referirse a los ministerios (en realidad consejerías) de educación enfatiza e intensifica lo que está intentando expresar. Por último, remata el texto con un Me encanta la situación. Qué feliz!, claramente irónico, que le ayudan a reforzar la crítica que estaba llevando a cabo con el resto de sus palabras. Cabe preguntarse a quién se dirige Somin. La mayoría de sus entradas se escriben en coreano, aunque una parte significativa de ellas, mientas residía en España (regresa a Corea, después de ocho años en Madrid, en junio de 2015), se escriben en español, generalmente con una traducción o acompañamiento en coreano. Son frecuentes entre sus entradas en español 
aquellas que describen su cotidianidad: dónde está, lo que hace, sus estudios, sus relaciones personales, etc.

Escribe, además, otro tipo de textos en español como el que acabo de comentar en los que deja patente cómo se siente respecto a España y su cultura. Curiosamente, a todas las personas a las que gusta el texto son coreanas, menos una, y todos los comentarios, menos uno también, están también escritos en coreano. Poco después, el 22 de abril de 2015, en Facebook también, ironiza sobre una visita a un centro institucional.

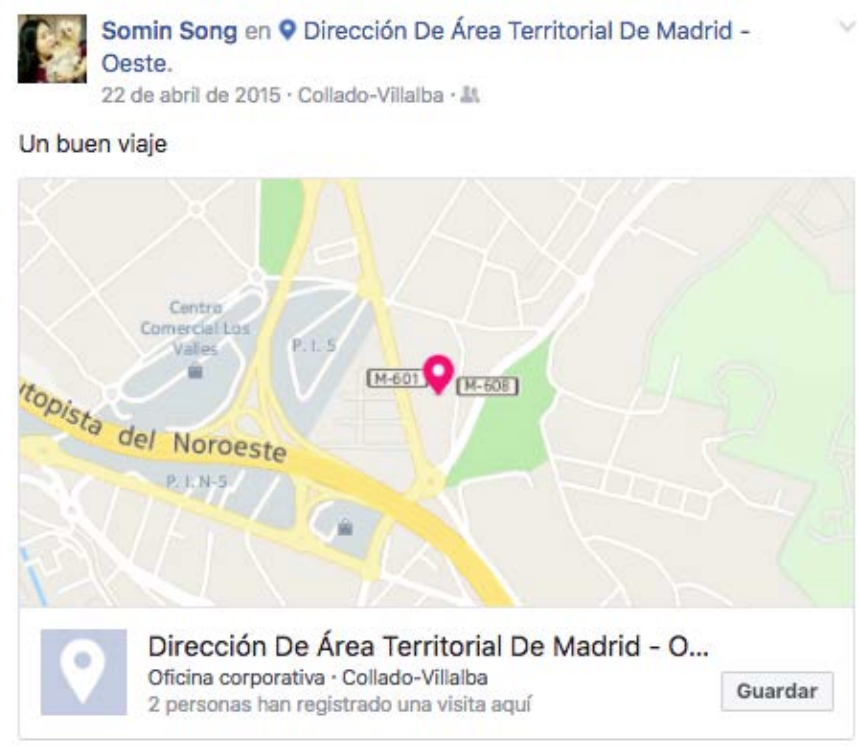

De alguna manera, Somin decide manifestarse claramente en contra de algunos de los valores que representan la cultura de la comunidad discursiva dominante. Sus críticas, formuladas además en español, la posicionan contra unas convenciones impuestas que no acepta, y tomando partido por una identidad alternativa, sin complacencias hacia las opciones que se le presentan. La ironía sirve para reforzar la relación que mantiene con sus interlocutores, facilitando su identificación. En el caso de Somin esta identificación no parece producirse con el grupo social dominante, sino con los amigos coreanos que se han podido sentir en las mismas circunstancias durante su estancia en España.

En cualquier caso, no debemos entender este posicionamiento como estático. Hay ocasiones en las que Somin se posiciona de maneras diferentes, en función de la faceta de su vida o del punto de vista que quiere 
expresar. Esta aparente heterogeneidad nos puede llevar a percibir contradicciones en las diferentes maneras en que los autores deciden presentarse a sí mismos, y puede ser más evidente o característica en aquellos que pretenden entrar en una nueva comunidad. En el caso de Somin, la ironía y el sarcasmo que emplea para cuestionar abiertamente algunos de los mitos que dominan el modelo cultural español (el orgullo de ser español), se reemplazan por el entusiasmo y excitación con los que describe los éxitos deportivos de algunos equipos de fútbol españoles, como en el siguiente ejemplo, aunque no es el único similar, que comparte el 25 de mayo de 2014 en su timeline de Facebook.

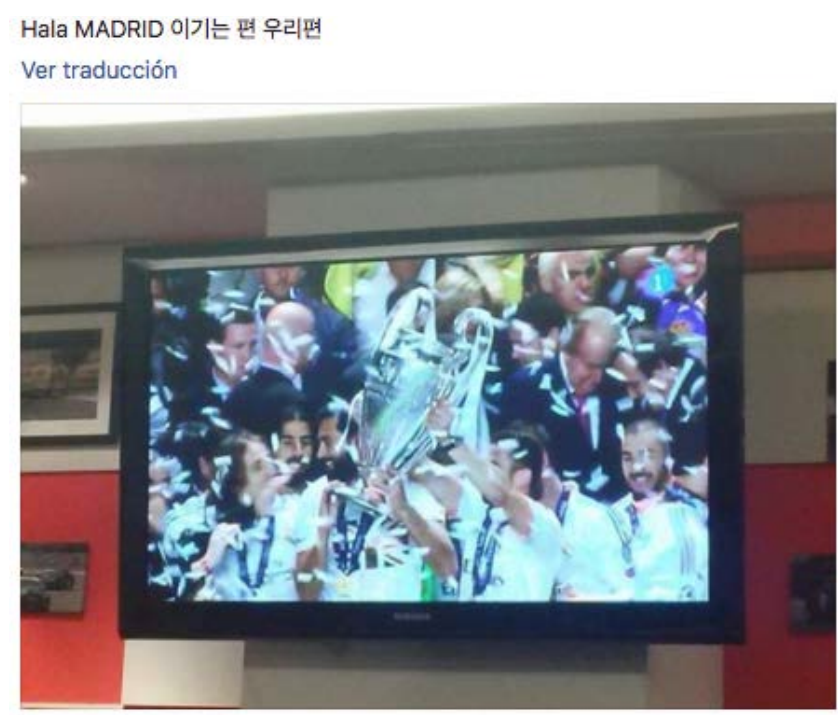

Gee (1999) recuerda cómo los distintos modelos culturales de diferentes grupos sociales y culturales de personas suponen siempre ideas encontradas acerca de lo que hace que una persona o acción sea "aceptable" o "valiosa". De la misma manera, es imposible aprender una lengua sin aprender cuáles son los modelos culturales predominantes en la sociedad en la que se vive, teniendo en cuenta los valores y las realidades en las que están insertos. Estos modelos culturales, de nuevo siguiendo a Gee, están presentes en la cultura en la que vivimos: aparecen en los medios de comunicación, en los materiales escritos, en las interacciones con otras personas de la sociedad, etc. Es decir, es imposible sustraerse a su influencia, aunque sea para rechazarla. Somin es por tanto consciente del significado de las palabras que utiliza en su texto, y del valor que para una 
parte representativa de españoles pueden significar, y decide subvertirlo: los valores propios de la cultura mayoritaria no son los suyos, la aceptación sin más, sin cierta resistencia, de la idea de que ser español es un orgullo, no forman parte de su identidad social.

En cualquier caso, Somin, manifiesta tener una buena opinión del país y de sus experiencias aquí y matiza cuáles fueron las razones para escribir un mensaje con una carga crítica importante hacia el país donde vivía en ese momento y la manera en la que se gestionan los trámites en las administraciones.

Somin: (De) vez de cuando encontraba unos locos racistas por la calle, por ejemplo, que (intentaban) asustarme de "broma". No sé si los españoles están (de acuerdo con) que son racistas los que asustan (a) las extranjeras. Normalmente (asustan a) las chicas, mujeres, pero yo pienso que sí. Pero casi todos los españoles que me encontraban durante ocho años de mi vida en España han sido buenos, por eso siempre digo, a (quien) me pregunta sobre España, que los españoles son simpáticos y que no hace falta que se preocupe cuando visita o viaja a España.

No todos los estudiantes reflejan de la misma manera los sentimientos encontrados o sus ambivalencias hacia el grupo social o la cultura mayoritaria, en este caso representada por los españoles y los hablantes nativos de español. Para Sam, un estudiante coreano, como Somin, hay distinciones significativas entre los diferentes grupos sociales de los que forma parte: jóvenes estudiantes coreanos y jóvenes estudiantes españoles. Estas diferencias se hacen patentes, por ejemplo, en la manera en que unos y otros emplean sus perfiles de Facebook e Instagram para comunicarse.

Sam escribe fundamentalmente en coreano, para que sus amigos de Corea puedan saber qué es lo que hace en España. Cuando escribe en español, en cambio, su intención es que sus amigos y compañeros de clase españoles puedan conocer más sobre su país y, en algunos casos también, preguntarles directamente sobre el contenido o actividades de los cursos que comparten. No le preocupa tanto el hecho de que pueda cometer errores, una preocupación muy común entre los estudiantes de español cuando deben comunicarse con nativos en público, sino que no lleguen a entender lo que realmente quiere decir. Es decir, que se produzcan malentendidos no de tipo gramatical, léxicos, etc., sino culturales: 
Sam: Es mi opinión personal pero creo que los coreanos usan Facebook como una (manera) de comunicar como que están junto en mismo lugar, pero en España cuidan un poco más de su privacidad. (...) hmm..... no sé si es buen ejemplo o no pero cuando subo un selfie mis amigos coreanos comentan como "¿qué tal?" y empiezan hablar de nuestra vida reciente, pero los españoles no lo hacen. (...) (Los españoles) Sí que comentan pero en plan... que guapo o saliste bien así (...) y si quieren decirme algo me (lo) dicen por chat de FB, no por comentarios.

Sin embargo, aunque le preocupa no ser capaz de interactuar correctamente en Facebook e Instagram por las dificultades que percibe sobre el significado y valor de las palabras, los modelos culturales y los lenguajes sociales de los que quiere formar parte, intenta en algunas de sus entradas asumir los valores con los que se les identifica. Así, el 6 de julio de 2015 cuelga una imagen, sin ningún otro texto, de una comunidad de humor española muy popular entre jóvenes de su edad, Cabronazi.
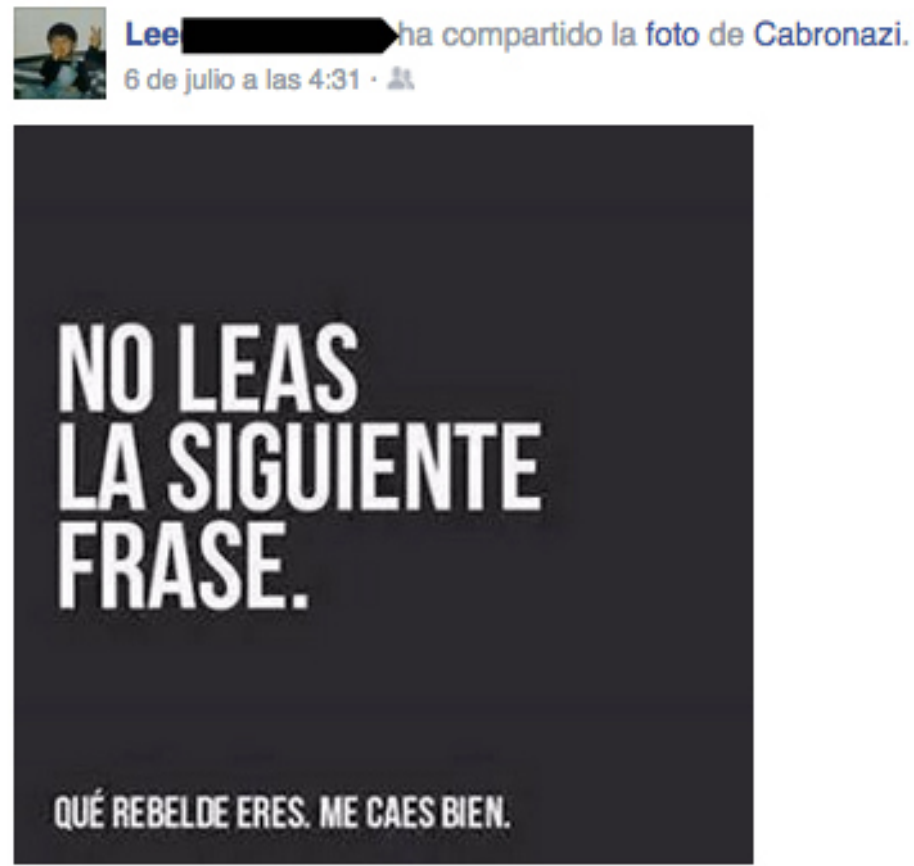

Me gusta · Comentar - Compartir 
De la misma manera, un mes antes, el 3 de junio de 2015, cuelga el enlace de una banda española, DVCIO, de nuevo sin ningún texto o comentario por su parte.
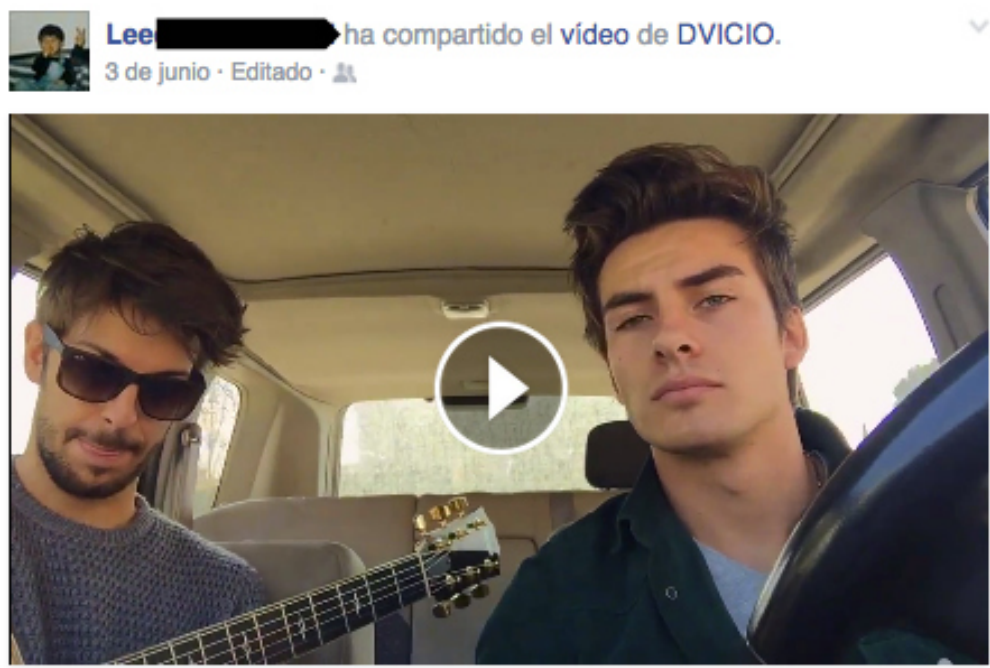

26979200 reproducciones

Guardar este video

DVICIO ha subido un video nuevo.

ENAMORATE EN EL COCHE

Me gusta - Comentar - Compartir

Ambas entradas son un intento de amoldarse al grupo social, jóvenes estudiantes como él, asumiendo como propios sus gustos y actividades principales. Hay también una intención de dar a conocer a sus amigos en Corea no solo determinados elementos de la cultura española, sino su papel de "experto", porque lleva viviendo en Madrid un tiempo. Sam es muy consciente del tipo de contenido que comparte, pero también de cómo se proyecta su imagen e identidad en sus perfiles de Facebook e Instagram: (escribo) en manera de no quejar mucho o no sea demasiado sentimental así jaja...

Es especialmente cuidadoso, por otra parte, con la manera en la que refleja su vida en España o los problemas o dificultades a las que se puede enfrentar: por ejemplo, (para) mi los dos países son muy importante, así que cuando estoy deprimido por racismo, no lo (escribo) por FB (...) A los españoles les (parecerá que critico a) España, y a los coreanos les darán mala imagen de España. Hay una intención de no ofrecer una imagen 
negativa ni de sí mismo, ni sobre el papel que como coreano está representando en España, ya que en cualquiera de los dos casos se podría interpretar como una crítica hacia sus aspiraciones de formar parte de esa comunidad o grupo social.

Hay ocasiones, sin embargo, en las que la discordancia entre lo que probablemente sea más aceptado en su cultura en el contexto de uso de sus perfiles de Facebook e Instagram está más acentuado. De esta manera, comparte situaciones que pueden proyectar una imagen no tan favorecedora de sí mismo para sus amigos o compañeros de clase españoles, como en esta entrada escrita en coreano y español en Instagram y compartida el 1 de diciembre de 2015.
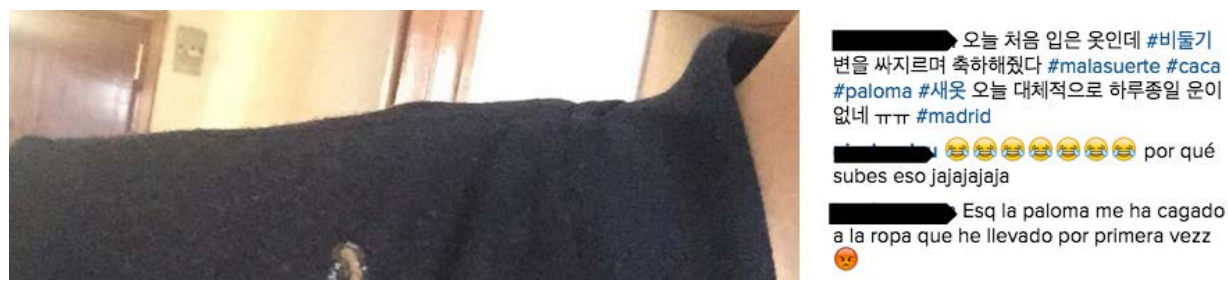

Es decir, una gran mayoría de jóvenes españoles de su edad evitarían compartir determinados contenidos o material que podrían proyectar una imagen distorsionada de ellos mismos, mientras que para Sam una anécdota como esta no representa ninguna agresión contra la identidad que se percibe en sus perfiles, y sí es susceptible de hacerla pública en su cuenta de Instagram.

\section{ConClusiones}

Los ejemplos mostrados en el cuerpo del trabajo muestran la necesidad de poner el foco de la escritura como un proceso de auto representación o identificación de los autores, es decir, tener una visión social de la escritura, en lugar de abordarla como el producto de un individuo concreto. Cada uno de los participantes tiene una idea muy diferente de sí mismos, de cómo quieren e intentan que los demás les vean a través de los que muestran, escriben y comparten en Facebook e Instagram; y de cómo es su relación también con el país en el que viven o vivían en el momento de la investigación. En ambas redes, es posible que se exagere o enfatice aspectos de su personalidad que son difícilmente perceptibles por personas con las que apenas tienen contacto o confianza en otros entornos. Desde esta 
perspectiva, se produce un despliegue de recursos (el uso de otras lenguas sería uno de ellos) que amplifica sus habilidades, conocimientos e incluso su personalidad. Ahora bien, el medio no es totalmente determinante a la hora de elegir qué papeles despliegan, o la relación que quieren mantener con sus interlocutores. Son los usuarios, en la medida de las posibilidades que les ofrecen estos entornos tecnológicamente mediados, quienes deciden transgredir las reglas o limitaciones impuestas por su diseño en función de sus necesidades expresivas, de comunicación, de conexión con los demás, etc.

Por otra parte, Facebook e Instagram se revelan a lo largo del proceso de investigación como lugares donde es posible no solo interactuar y relacionarse con los demás. Son también los espacios donde se llevan a cabo procesos relacionados con el aprendizaje, en este caso de una lengua, y de creación discursiva de su identidad dentro de una comunidad o grupo social, integrada por personas con las que la conexión es diversa y cambiante. Sus textos son vehículo tanto de su yo discursivo como de las ideas y creencias a las que quieren dar voz, a través de distintos procedimientos.

Debe recordarse que al tratarse de un estudio cualitativo con una muestra tan pequeña ${ }^{4}$, los ejemplos y contabilización de los papeles que adoptan en las interacciones comunicativas que mantienen en línea no tiene la intención de señalar qué datos son o no significativos. Se ha intentado, por el contrario, integrar un análisis más detallado de los ejemplos que se ofrecen, con una visión global sobre el tipo de textos que han escrito o compartido en español a lo largo de un determinado periodo de tiempo ${ }^{5}$.

La función principal de la contabilización de los papeles comunicativos y la manifestación de la distancia social ha sido, por tanto, guiarme durante la investigación para poder hacer interpretaciones sobre sus textos, orientadas hacia las preguntas sobre las que reposa el trabajo de esta tesis, que se detallarán de manera más completa en las conclusiones finales de la misma.

En definitiva, el análisis de los textos de cada uno de los sujetos participantes relacionado con aspectos diferentes (la identidad, el uso de lenguas, la distancia social y el uso de imágenes) ha mostrado resultados que aunque no pueden ser generalizados al resto de usuarios, sí pueden dar pautas para entender algunas de las prácticas letradas en espacios digitales:

\footnotetext{
${ }^{4}$ Participaron 11 estudiantes de orígenes y procedencias diferentes. Por motivos de espacio en el artículo se ofrecen los ejemplos y opiniones de solo siete de ellos.

${ }^{5}$ Los textos fueron escritos y compartidos entre 2013 y 2017.
} 
intertextualidad y apropiación de otras voces (el uso de citas, la reproducción o la adaptación de las palabras de otros e incluso del contenido creado por otros); fluidez de géneros y prácticas letradas; convergencia entre distintas plataformas; etc. Las actividades letradas existen y se desarrollan gracias a las prácticas sociales en las que se encuentran inmersas, y así se aborda en el trabajo el uso que hacen los participantes de plataformas en línea para posicionarse y expresar sus opiniones y actitudes hacia determinados temas, de mostrar su vida a través de textos, imágenes y todo tipo de elementos audiovisuales y multimodales.

En este sentido, es inevitable llegar a la conclusión de que lo que se escribe o comparte en línea transmite de manera directa o indirecta información a los receptores (en la mayor parte de los casos una audiencia formada por desconocidos) sobre el autor, aunque estos puedan no percibirlo de esta forma. La función de los docentes de lenguas extranjeras sería doble. Por una parte la de ayudar a los estudiantes a ser conscientes acerca de cómo proyectan su identidad personal y cultural sobre lo que escriben y el contenido que comparten, especialmente si consideramos que lo hacen en espacios públicos o semipúblicos, frente a una audiencia global, en una lengua que no es la suya. Por otra, reconocer las diferencias entre los tipos de voces, géneros y discursos, de la lengua que están aprendiendo. De esta forma, tener en cuenta cómo emplean los estudiantes la lengua en espacios digitales puede ser de gran ayuda, pues en ellos tiene lugar también una amalgama de voces, géneros y discursos, en infinidad de lenguas, con la posibilidad de que además pueden llegar a ser leídos por una cantidad ingente de personas con los que el nexo de unión es variable y en ocasiones muy difuso.

\section{BIBLIOGRAFÍA}

Androutsopoulos J. (2010). Localising the global on the participatory web. En Coupland, N. (ed.). Handbook of Language and Globalisation (pp. 203-231). Oxford, UK: Blackwell.

Authier, J. (1982). “Hétérogénéité montrée et hétérogénéité constitutive: éléments pour une approche de l'autre dans le discours”, DRLV, 26.

Bajtín, M. (1934-1935). Discourse in the novel. En The Dialogic Imagination. Austin, USA: University of Texas Press, 1981, pp. 259-422. 
Baron, N. (2003). "Why emmail looks like speech: proofreading, pedagogy, and public face". En Aitchison, J. y Lewis, D. (eds.). New Media Language. London, UK: Routledge.

Baron, N. S., Squires, L., Tench, S., y Thompson, M. (2005). Tethered or Mobile? Use of Away Messages in Instant Messaging by American College Students. En Mobile Communication. Re-negotiation of the Social Sphere (pp. 285- 293). Ling, L., y Pedersen, P. E. (eds.). Kent, UK: Springer-Verlag.

Barton, D. (2007). Literacy. An Introduction to the Ecology of Written Language.Singapore: Blackwell Publishing.

Barton, D. y Lee, C. (2013). Language Online. Investigating Digital Texts and Practices. New York, USA: Routledge.

Blommaert, J. (ed.). (1999). Language Ideological Debates. Berlin, Germany: Walter de Gruyter.

Casalmiglia, H. y Tusón, A., (1999, ed. 2007). Las cosas del decir. Barcelona, España: Ariel Lingüística.

Cherny, L. (1999). Conversation and Community: Chat in a Virtual World. California, USA: CSLI Publications.

Chun, E. y Walters, K. (2011). Orienting to Arab Orientalism: language, race, and humor in a Youtube video. En Thurlow, C., y Mroczek, K. (eds.). Digital Discourse and the New Media. London, UK: Oxford University Press.

Clark, R. y Ivanic, R. (1997). The Politics of Writing. New York, USA: Routledge.

Crystal, D. (2006). Language and the Internet. Cambridge, UK: Cambridge University Press.

Danet, B. (1998). Text as mask: gender, play, and performance on the net. En Jones, S. G. (ed.). Cyberspace 2.0: Revisiting Computer Mediated Communication and Community. California, USA: Sage Publications.

Gee, J. (1990). La ideología en los Discursos. Madrid, España: Morata Ediciones, 2005.

Gee, J.P. (1999). An Introduction to Discourse Analysis. Theory and Method. New York, USA: Routledge, 2014.

Giltrow, J. y Stein, D. (eds.). (2009). Genres in the Internet: Issues in the Theory of Genre. Amsterdam, The Netherlands: John Benjamins. 
Herring, S. C. (1996). "Two variants of an electronic message schema". En Herring, S. C. (ed.). Computer-Mediated Communication: Linguistic, Social and Cross- Cultural Perspectives. Amsterdam, The Netherlands: John Benjamins.

Herring, S. C. (2002). "Computer-mediated commounication on the Internet". Annual Review of Information Science and Technology, 36, pp. 109-168.

Hine, C. (2015). Ethnography for the Internet: Embedded, Embodied and Everyday. London, UK: Bloomsbury.

Hymes, D. H. (1972). Models of the Interaction of Language and Social Life. En Gumperz, J. J. y Hymes, D. H. (eds.). Directions in sociolinguistics. The ethnography of communication. New York, USA: Blackwell, pp. 35-71.

Ivanič, R. (1998). Writing and Identity. The Discoursal Construction of Identity in Academic Writing. Amsterdam, The Netherlands: John Benjamins Publications.

Krees, G. y Leeuwen, T. (2001). Multimodal Discourse. The Modes and Media of Contemporary Communication. London, UK: Hodder Education.

Lave, J. y Wenger, E. (1991, ed. 2011). Situated Learning. Legitimate Peripheral Participation. Cambridge, UK: Cambridge University Press.

Lee, C. (2011). Digital Discourse. Language on the New Media. En Thurlow, C., Mroczek, K (eds.). Micro-Blogging and Status Updates on Facebook: Text and Practices (pp.110-128). London, UK: Oxford University Press.

Lee, C. (2017). Multilingualism Online. New York, USA: Routledge.

Myers, G. (2010). "Stance-taking and public discussion in blogs". Critical Discourse Studies, 7, (4), pp. 263-275.

Norton, B. (2000). Identity and Language Learning: Gender, Ethnicity, and Educational Change. Essex, UK: Longman.

Page, R. (2012). Stories and Social Media. London, UK: Routledge.

Reyes, G. (1990). La pragmática lingüística. El estudio del uso del lenguaje. Barcelona, España: Montesinos.

Reyes, G. (1994). Los procedimientos de cita: citas encubiertas y ecos. Madrid, España: Arco Libros.

Tagg, C. (2012). Discourse of Text Messaging London, UK: Continuum. 
Thurlow, C. y Jaworski, A. (2011). "Banal globalization? Embodied actions and mediated practices in tourists' online photo sharing". En Thurlow, C. y Mroczek, K. (eds.). Digital Discourse: Language in the New Media. London, UK: Oxford University Press.

Wenger, E. (1998). Communities of Practice. Learning, Meaning, and Identity. Cambridge, UK: Cambridge University Press.

Werstsch, J. V. (1991). Voices of the Mind. A Sociocultural Approach to Mediated Action. Cambridge, USA: Harvard University Press.

Zhao, D., Grasmuck, S. y Martin, J. (2008). Identity construction on Facebook: Digital empowerment in anchored relationships. Computers in Human Behavoir, 24, pp. 1816-1836. 